\title{
Considerações teórico-metodológicas sobre a história do campo da Economia Política da Comunicação e da Cultura
}

\author{
César Ricardo Siqueira BOLAÑO ${ }^{1}$ \\ Verlane Aragão SANTOS ${ }^{2}$
}

\begin{abstract}
Resumo:
O objetivo deste texto é demarcar alguns elementos teóricos para o estudo da história da Economia Política da Comunicação e da Cultura (EPC) brasileira, entendida como campo científico, sem deixar de levar em consideração a sua inserção no campo da Comunicação. Depois de uma discussão sobre temas de história e epistemologia do campo, é apresentado um sumário relativo ao problema da periodização do objeto mais tradicional da EPC brasileira, o mercado de televisão.

Palavras chave:

Economia política. Comunicação. História. Epistemologia.

\section{Theoretical and epistemological considerations on the history of} the field of the Political Economy of Communication and Culture
\end{abstract}

\author{
Abstract: \\ This paper aims to define some theoretical elements in order to study the history of the Brazilian Political \\ Economy of Communication and Culture (PEC), considered as a scientific field inserted in the field of \\ Communication as a whole. First we discuss certain themes related to the field's history and epistemology \\ and after we present a summary on the problem of periodization of the most traditional object of the \\ Brazilian PEC, the television market. \\ Keywords: \\ Political economy. Communication. History. Epistemology.

\section{Consideraciones teórico-metodológicas sobre lahistoriadel campo de laEconomía Política de laComunicación y de la Cultura}

Resumen:

El objetivo de este texto es demarcar algunos elementos teóricos para elestudio de lahistoria de laEconomía Política de laComunicación y de la Cultura (EPC) brasileña, entendida como campo científico, llevandoenconsideraciónsuinserciónenel campo de laComunicación. Despues de una discusión sobre temas de historia y epistemologíadel campo, se presenta un sumario relativo al problema de laperiodizacióndel objeto más tradicional de la EPC brasileña, el mercado de televisión.

Palabras clave:

Economía política. Comunicación. Historia. Epistemología.

\section{Introdução}

O objetivo deste texto é demarcar alguns elementos teóricos para o estudo da história da Economia Política da Comunicação e da Cultura (EPC) brasileira, entendida como campo científico, sem deixar de levar em consideração a sua inserção no campo da Comunicação. Poder-se-ia falar em subcampo, mas essa seria já uma solução e talvez

\footnotetext{
1 Professor da Universidade Federal de Sergipe, membro do grupo OBSCOM/CEPOS do CNPq e presidente da ULEPICC-Brasil. E-mail: bolano.ufs@gmail.com

2 Professora da Universidade Federal de Sergipe, membro do grupo OBSCOM/CEPOS do CNPq e tesoureira da ULEPICC-Brasil. E-mail:velorca2010@gmail.com
} 
simples demais, pois estamos falando, por um lado, no caso das chamadas Ciências da Comunicação, de uma área de conhecimento geralmente apresentada por seus representantes como essencialmente interdisciplinar, recolhendo contribuições as mais variadas, algumas ligadas à Sociologia da Cultura, à Sociologia Política, à Antropologia e outras disciplinas acadêmicas que incorporaram, em diferentes medidas, temas de Economia Política.

Por outro lado, a EPC, em nível mundial e também no Brasil, inclui-se desde os seus inícios no pensamento marxista, recolhendo, por certo, metodologias e mesmo aportes teóricos parciais desenvolvidos pela economia acadêmica em geral, e também de outros campos, mas evitando todo ecletismo, mantendo-se fiel ao grande legado do materialismo histórico. Inscreve-se, assim, numa tradição intelectual que não aceita os limites impostos pela departamentalização do saber, buscando, ao contrário, entender o ser social em sua totalidade. No caso da EPC brasileira, ademais, a influência do estruturalismo-histórico latino-americano, também preocupado, no campo da economia, como o marxismo, com os fatores extraeconômicos, reafirma a tendência interdisciplinar que, em certo momento, no pensamento de Furtado (1977), aparece sob a forma de um projeto de construção de uma Ciência Social global.

O foco aqui é o campo da EPC apenas, considerando não só os objetos e as metodologias que a disciplina acaba incorporando, mas também e principalmente a sua institucionalidade, tal como foi sendo construída. Interessa demarcar as particularidades da EPC brasileira e sua influência no campo que vem se unificando em nível internacional, especialmente após 1992, ano do I Congresso da Associação Latinoamericana de Investigadores da Comunicação (ALAIC), em Embu Guaçu, e da realização, à mesma época, do congresso do Guarujá da InternationalAssociation for Media and Communication Research (IAMCR).

Outro problema teórico relativo ao estudo histórico no campo da EPC, a ser tratado na segunda parte deste artigo, refere-se à periodização e pode ser proposto inicialmente em termos da dupla determinação, interna/externa, na definição dos pontos de corte. Em Mercado brasileiro de televisão (BOLAÑO, 1988), ao contrário das periodizações anteriores, define-se um único elemento interno, ligado ao estudo das estruturas de mercado em oligopólio, de modo a garantir uma definição rigorosa e homogênea, considerando, não obstante, a necessidade de articular, a cada momento, duas outras ordens de determinação externa: tecnologia e regulação. Esta última remete 
para questões políticas, fundamentais no caso de um sistema que se encontra no centro dos processos de construção da hegemonia, enquanto a primeira pode ser entendida a partir da constatação de que as trajetórias tecnológicas do audiovisual são determinadas externamente por aquelas de setores como as telecomunicações e a informática.

$\mathrm{O}$ aspecto mais interessante desse segundo problema, que remete novamente para as questões de fundo acima referidas e discutidas na primeira parte deste artigo, refere-se ao fato de que as mudanças em relação ao objeto da Comunicação (Indústria Cultural, TV de massa, Internet) implicam mudanças na própria delimitação da disciplina. Assim, a história do objeto e a história do campo se entrelaçam, como não poderia deixar de ser, e as soluções dadas a cada momento são responsáveis pela maior ou menor incidência de uma ou outra corrente teórica, paradigma etc. Com a referida tendência de unificação do campo da EPC em nível internacional, num momento em que ganha relevância no interior dos estudos de Comunicação, torna-se crucial retomar o debate epistemológico à luz das grandes transformações por que passa o nosso objeto a partir da consolidação da Internet como espaço de acumulação de capital e de construção de hegemonia em nível nacional e global.

Sem nos afastarmos do modelo teórico proposto por Bourdieu, podemos dizer que a definição de um campo envolve elementos não apenas de ordem epistemológica, mas também institucional, que delimitam a dinâmica de construção da hegemonia entre grupos, paradigmas, programas de investigação, no seu interior. Assim, "a permanente disputa pela legitimidade por parte de indivíduos e grupos com competência cognitiva, conhecedores do paradigma, se quisermos, mas que se encontram afastados dos núcleos institucionais em que a hegemonia se exerce, é um elemento fundamental na dinâmica dos diferentes campos" (BOLAÑO, 2015, p. 82). Nas palavras do próprio Bourdieu, referindo-se especificamente ao campo científico, temos que este,

[...]enquanto sistema de relações objetivas entre posições adquiridas (em lutas anteriores), é o lugar, o espaço de jogo de uma luta concorrencial. O que está em jogo especificamente nessa luta é o monopólio da autoridade científica definida, de maneira inseparável, como capacidade técnica e poder social; ou, se quisermos, o monopólio da competência científica, compreendida enquanto capacidade de falar e agir legitimamente (isto é, de maneira autorizada e com autoridade), que é socialmente outorgada a um agente determinado. (BOURDIEU, 1983, p. 122). 
Nesse espaço de disputa, a luta epistemológica - nunca desassociada da luta política - constitui-se em face da apropriação do campo em que o capital econômico converte-se em capital simbólico. Interpretando outro trecho de Bourdieu (1977), Bolaño conclui que "não se deve esperar... que a inovação radical venha do centro, nem tampouco, por certo, de fora do campo. É na periferia onde devem ser procurados os sinais de ruptura" (BOLAÑO, 2015, p. 83). A disputa impele e exige a ocupação dos espaços de legitimação.

No caso dos movimentos de institucionalização da EPC brasileira, que levariam a sua constituição como campo vinculado às chamadas Ciências da Comunicação, darse-á a partir da sua organização como grupo de trabalho no interior do movimento de criação dos primeiros sistemas grupos de trabalho da Associação Latino-americana de Pesquisadores da Comunicação (ALAIC) e da Sociedade Brasileira de Estudos Interdisciplinares da Comunicação (INTERCOM) - aos quais se deve agregar o hoje desativado GT EPC da Associação dos Programas de Pós-Graduação em Comunicação (COMPÓS) - a partir de 1992 e, depois disso, com a criação da Revista EPTIC Online (1999) e da Rede EPTIC e a fundação da União Latina de Economia Política da Informação da Comunicação e da Cultura (ULEPICC), em 2002 em Sevilha, fortemente vinculada, na sua gênese, ao campo latino-americano e, sobretudo, brasileiro.

No que se refere ao aspecto epistemológico da constituição do campo como programa de investigação, a importância de estudar a sua gênese e desenvolvimento vincula-se fundamentalmente à necessidade de entender não apenas as influências que continuam atuando mesmo depois de constituído, mas também para o que se poderia chamar uma "arqueologia" do campo, com potencial para revelar possibilidades adormecidas que acabaram não sendo incorporadas ao corpus consolidado da disciplina, mas podem indicar linhas de pesquisa potencialmente ricas em momentos de profundas mudanças nos objetos, ${ }^{3}$ como ocorre neste momento, por exemplo, com a transição da

\footnotetext{
3 A problemática da "arqueologia do saber" é posta especialmente por Foucault, ainda que em outra perspectiva, diferenciando-a da história das ideias. A certa altura, ele afirma: "ocupar-se do funcionamento ideológico de uma ciência para fazê-lo aparecer ou para modificá-lo, não é trazer à luz os pressupostos filosóficos que podem habitá-la; não é voltar aos fundamentos que a fizeram possível e que a legitimam: é voltar a pô-la em discussão como formação discursiva; é ocupar-se não das contradições formais de suas proposições, senão do sistema de formação de seus objetos, de suas eleições teóricas. É reassumi-la como prática entre outras práticas" (FOUCAULT, 1970, p. 313). A análise do discurso está fora do escopo deste artigo, mas pode ser útil, como ferramenta metodológica, justamente na análise arqueológica que vimos sugerindo. O próprio Foucault cita o exemplo da economia política, lembrando que "se pode reconhecer, no século XVII, um umbral de positividade" que "coincide com a prática e a teoria do mercantilismo; mas a sua epistemologização não haveria de produzir-se até ... Locke e Cantillon. Sem embargo, o século XIX, com Ricardo, assinala ao mesmo tempo um novo tipo de positividade, uma nova epistemologização, que Cournot e Jevons haveriam de modificar, por sua vez, na
} 
velha Indústria Cultural do século XX para a nova estrutura de legitimação e de produção simbólica do capitalismo, o objeto por excelência da EPC.

No caso da EPC brasileira, Mercado brasileiro de televisão tem sido considerado a obra fundadora (BRITTOS, 2008; SIMIS; LOPES, 2010). O livro, de 1988, é resultado da dissertação de mestrado defendida em 1986. À época, já haviam sido publicadas uma série de contribuições precursoras, entre as quais destaca-se Televisão $e$ capitalismo, de Sérgio Capparelli (1984, "uma pesquisa com forte matriz sociológica e, em consonância com seu tempo histórico, baseada nas teorias da Dependência Cultural" (BRITTOS, 2008, p. 198). Outros, no entanto, poderiam ser citados. O próprio Bolaño (1988, 2000) realiza uma pequena arqueologia, citando autores brasileiros e latinoamericanos, no intuito de dar à sua contribuição aquele caráter de síntese próprio também das obras fundacionais.

José Marques de Mello, por sua vez, define o artigo de Bolaño de 1987, publicado na Revista Brasileira de Ciências da Comunicação (RBCC), como marco inaugural, e inclui entre os precursores autores inusitados, como Barbosa Lima Sobrinho, Costa Rêgo, Manuel Correia de Andrade, Celso Furtado, entre outros (MELO, J. M.; MELO, P. B., 2013). Neste caso, define-se Economia Política em termos mais amplos do que aqueles que acabaram por demarcar o campo, basicamente vinculado ao marxismo, ou seja, mais rigorosamente, à Crítica da Economia Política, o que se justifica pelo fato de que, no próprio campo da Economia, os grupos de Economia Política são aqueles que aglutinam hoje o marxismo e as diferentes linhas de pensamento chamado heterodoxo, que não têm maior incidência sobre o campo da comunicação.

O recorte definido por Valério Brittos e geralmente aceito na EPC brasileira é certamente mais adequado do ponto de vista epistemológico, visto que é no livro de 1988 onde as problemáticas específicas e as metodologias - articulando elementos do materialismo histórico e do estruturalismo histórico latino-americano - são apresentadas de forma completa e sintética, ainda que a síntese só viesse a ser completada por Bolaño, considerando a maioria das escolas estrangeiras ainda desconhecidas naquela primeira contribuição, na sua tese de doutoramento, de 1993, revista em 1997 e

época mesma em que Marx, a partir da economia política, faria aparecer uma prática discursiva inteiramente nova" (FOUCAULT, 1970, p. 316). Vamos nos referir acima, brevemente, à história do pensamento econômico, na nossa própria perspectiva (marxista). A referência aqui a Foucault serve apenas para sinalizar o interesse da incorporação da sua contribuição para uma abordagem histórica da crítica da economia política da comunicação e da cultura, como sugerido neste artigo. 
publicada em 2000. A definição de Melo, em todo caso, enfatiza o elemento institucional da formação do campo no interior da INTERCOM, entidade editora da RBCC e que albergaria em seguida o primeiro grupo de EPC da América Latina, acima referido.

Seja como for, o que opera em direção ao privilégio da aceitação de uma obra como inaugural de um campo científico é a conjugação de uma série de fatores. Um paralelo poderia aqui ser feito com a própria ciência econômica. Assim, na Economia Política, como era designada a nova ciência, obras importantes antecederam A riqueza das nações, de 1776, de Smith, as quais trouxeram elementos essenciais para o desenvolvimento do novo campo. Assim, os fisiocratas, entre as décadas de 50 e 70 do século XVIII na França pré-revolucionária, já tinham conceituado e problematizado a categoria excedente, fundamental nas discussões sobre o processo de acumulação de capital e, mais, tinham feito o deslocamento da análise da esfera da circulação, a que os mercantilistas se limitavam, para a esfera da produção.

A obra de Smith - e a de Ricardo, posteriormente -, ao sintetizar toda a produção anterior (mercantilista e fisiocrata) ${ }^{4}$, incorpora esses elementos, num contexto histórico diferenciado daquele dos fisiocratas (a Inglaterra da Revolução Industrial frente a uma França eminentemente agrícola) ${ }^{5}$ e institui, na sua obra,o recorte do objeto e do método que configurará o escopo de distinção da Economia como campo científico. É a partir daí que tudo o mais se desenvolverá, inclusive a contribuição de Marx, a qual, em termos da luta epistemológica no interior do campo, radicaliza o

\footnotetext{
${ }^{4}$ Assim, por exemplo, "o problema do mais-valor (rendimento), que havia sido posto pelos fisiocratas, agora era ligado diretamente à teoria do valor-trabalho esboçada pelos mercantilistas. É um dos grandes méritos de Smith o de ter realizado essa síntese" (RUBIN, 1927, p. 253).O que está perfeitamente de acordo com a avaliação do próprio Marx, por exemplo, sobre as teorias do trabalho produtivo e improdutivo, quando afirma, a respeito do que considera o lado correto da perspectiva dualista de Smith, que a sua "concepção do trabalho produtivo deriva-se por si mesma da concepção que A. Smith tem acerca da origem da mais-valia, quer dizer, acerca da essência do capital. Lá onde professa essa concepção adota a tendência sustentada pelos fisiocratas e inclusive pelos mercantilistas, limitando-se a depurá-la de uma falsa interpretação e, portanto, a desentranhar o seu miolo interior" (MARX, 18621863, p. 138). É mérito de Rubin, seguindo a trilha de Marx, ressaltar a importância, na história do pensamento econômico, da contribuição dos mercantilistas na formação do pensamento econômico.

${ }^{5}$ Isaac Rubin, em sua história do pensamento econômico, enfatiza a determinação histórica das diferentes teorias estudadas, apontando, por exemplo, que, enquanto Smith pode ser definido como o economista do período manufatureiro na Inglaterra, Ricardo representa já um tipo de pensamento mais adequado à Revolução Industrial, o que tem evidentemente uma relação com a situação das lutas de classes - que, na época deste último, já opunham claramente, como contradição fundamental, burguesia e proletariado - e também com as opções em termos de fundamentação filosófica. Assim, "se a teoria do direito natural servira como base filosófica para as doutrinas dos fisiocratas e de Adam Smith, Ricardo e seus discípulos mais próximos foram adeptos fervorosos do utilitarismo" (RUBIN, 1927, p. 292), na medida em que já não se trata de defender o direito de todos os indivíduos igualmente, mas apenas a sua liberdade de escolha entre as opções postas pelo mercado.
} 
enfoque centrado na produção, nas relações sociais de produção, ou mais precisamente na contradição capital/trabalho, em relação à teoria do valor trabalho. A centralidade da produção não excluirá a relação dialética produção/circulação que se definirá no próprio método de exposição d'O Capital.

Se considerarmos agora os estudos da Escola de Frankfurt, referência fundadora para todo o pensamento crítico em Comunicação, há dois importantes aspectos a destacar que deveriam reorientar os estudos baseados na Economia Política na área. A despeito do enfoque dado à análise dos efeitos, em especial no público- que resiste até hoje (SODRÉ, 2012), especialmente no mainstream da área, mas também, com sinal invertido, em setores considerados críticos, como o dos estudos culturais (BOLAÑO, 2015) -, do desenvolvimento da chamada cultura de massa, a análise dos frankfurteanos recupera: (1) a centralidade da produção, ao apontar para a formação de um sistema de produção de mercadorias culturais, a partir do conceito (fundamental e de plena atualidade) de Indústria Cultural, e (2) o privilegio do método dialético (SLATER, 1978), alinhando-se, portanto, desde o início, não propriamente à Economia Política em geral, mas mais diretamente à sua crítica imanente, realizada por Marx.

Todas as diferentes escolas da EPC, em nível mundial, compartilham essa delimitação, situando-se sua especificidade, por certo, no terreno da Economia Política, ao contrário do enfoque filosófico geral frankfurteano, cuja recepção se dá sobretudo na sociologia e cujo reconhecimento, nesse sentido, na economia é posterior e, aliás, muito característico da EPC brasileira. $^{6}$

Todos esses meandros são ricos em pistas e problematizações e devem ser considerados na historiografia do campo. Inclusive o debate mais amplo em que os chamados precursores da economia política da comunicação e da cultura estavam inseridos - como, por exemplo, em nosso caso, autores críticos e marxistas da estatura de Adelmo Genro, de reconhecida importância nos estudos de jornalismo no Brasil, que tratava de muitos temas que a EPC também trata - deve ser considerado.

Assim também o conjunto dos autores das Teorias da Dependência ou do Imperialismo Cultural, cuja contribuição parece em geral mal interpretada na maioria das classificações produzidas no âmbito do pensamento comunicacional europeu e

\footnotetext{
${ }^{6}$ A economia francesa da comunicação e da cultura, por exemplo, na sua fundação, se propõe claramente como crítica à escola de Frankfurt, seguindo, aliás, a este respeito, as sugestões de Enzensberger (BOLAÑO, 2000; 2010). No caso da EPC brasileira, pode haver eventuais divergências e certamente há um deslocamento em direção à crítica da economia política, mas isso não se apresenta como proposta de uma alternativa geral e completa à teoria crítica da escola de Frankfurt.
} 
norte-americano, que acaba incluindo-as no terreno da EPC, sem perceber o que distingue uma e outra escola, ou melhor, sem considerar - certamente por deficiências teóricas próprias que não cabe discutir aqui - o fato essencial de que a obra dos autores da primeira escola crítica latino-americana não continha ainda, de um modo geral, os elementos de ordem epistemológica que definem o campo. ${ }^{7}$

Ora, numa abordagem que se pretende multidisciplinar e não meramente eclética, mas que atenda a critérios internos da disciplina, as contribuições precisam ser entendidas no interior de uma problemática econômica. Nesse sentido, não há dúvidas de que os primeiros trabalhos que, no Brasil, construíram esse tipo de problemática foram, por ordem cronológica, Mercado brasileiro de televisão (BOLAÑO, 1988), Economia da Cultura e da Comunicação (HERSCOVICI, 1995), ambos apoiados, evidentemente, no legado proveniente das contribuições de outros autores, ${ }^{8}$ o que não lhes retira o mérito de haver produzido a síntese originária, fundadora do campo da EPC brasileira.

Em seguida viriam o segundo livro de Bolaño (2000), a tese de doutoramento de Valério Brittos (Capitalismo contemporâneo, mercado brasileiro de televisão por assinatura e expansão transnacional, de 2001) e a de Ruy Sardinha Lopes (Informação, conhecimento e valor, de 2006). O campo se amplia muito ainda, se considerarmos as contribuições latino-americanas. Além disso, seria necessário verificar a influência que essas obras, uma vez constituído o campo, tiveram sobre autores importantes de outros campos especializados da comunicação, como os estudos de jornalismo, de rádio, a comunicação popular e alternativa, os estudos de cinema etc.

\section{II}

A evolução dos critérios de periodização da economia brasileira pode ser tomada como caso exemplar para o problema teórico que nos interessa neste ponto. Contra a velha ideia dos ciclos - do açúcar, das minas, do café etc. - a periodização de autores do estruturalismo histórico latino-americano, como Furtado, ou como a escola da UNICAMP, com forte influência marxista, pensam em termos da constituição das forças produtivas e das relações sociais capitalistas como um processo complexo que se

${ }_{7}$ A obra inicial de Armand Mattelart, da época chilena, é certamente diferenciada a este respeito, mas é evidente que a sua problemática ainda se define em termos muitos mais próximos de Lênin do que de Marx, ao contrário do que ocorrerá posteriormente.

${ }^{8}$ Neste caso, de duas origens muito distintas, quais sejam, a economia política brasileira, da escola da UNICAMP, e a economia da comunicação e da cultura francesa, o que explica em grande parte as suas diferenças. 
desdobra no tempo, a partir da constituição da economia colonial até a industrialização e a internalização das condições para a reprodução ampliada do capital, passando pela implantação da forma salarial, do mercado de trabalho livre, do Estado nacional, da circulação monetária, do surgimento de uma burguesia comercial nacional que realiza um processo de acumulação primitiva de capital que transbordará em seguida para a indústria nascente etc.

O debate neste caso é sobre a influência dos determinantes externos dessa evolução, pois se trata de um processo que não apenas reproduz internamente o desenvolvimento daquelas "invariantes estruturais", como diriam os autores da escola francesa da regulação, que caracterizam o modo de produção capitalista plenamente desenvolvido, como o faz sob condições de dependência externa, respondendo aos estímulos do processo de difusão da civilização industrial, nos termos de Furtado, a partir do seu núcleo originário, na Inglaterra. As formas como a economia nacional responderá a esses estímulos, em função da sua constelação de recursos, do estágio alcançado pelo desenvolvimento das forças produtivas internas a cada passo, pela inserção na divisão internacional do trabalho, determinarão as especificidades de cada caso nacional. Assim se distingue, em linhas mais gerais, o desenvolvimento do subdesenvolvimento, o centro das periferias etc.

Essa mesma lógica pode ser aplicada ao estudo da história de um objeto importante da EPC, como é o da televisão. As periodizações anteriores a Mercado brasileiro de televisão eram essencialmente externalistas, pautadas em elementos de ordem factual aleatória, em fatores puramente políticos - fazendo coincidir, por exemplo, os períodos com os dos governos nacionais - ou tecnológicos, ou recorrendo à história dos capitães da indústria, a exemplo da definição errada do conglomerado da TV Tupi e dos Diários Associados como oligopólio etc. Ao contrário, Mercado brasileiro... adota um critério homogêneo interno, com base nos conceitos definidores das estruturas de mercado, apresentando a evolução do sistema concorrencial dos anos 1950 ao oligopólio que se consolida na década de 70 do século XX, passando pelo período de transição, logo, explorando as mudanças estruturais segundo a dinâmica de construção, defesa e ruptura de barreiras à entrada, sob a pressão de elementos externos: políticos, refletidos no ambiente regulatório, e tecnológicos.

No caso da tecnologia, ressalte-se o fato, melhor explicado na segunda edição ampliada de Mercado brasileiro...(2004), de que as trajetórias tecnológicas do 
audiovisual são determinadas pela evolução daquelas de setores como as telecomunicações, a indústria eletroeletrônica e a informática, que estabelecem efetivamente a mudança estrutural. O próprio conceito de inovação na indústria de televisão está relacionado a elementos de outra ordem, de produção simbólica, inovação estética, em formatos, estruturas das grades de programação, modelos de negócio etc. Assim, o conceito de padrão tecnoestético (BOLAÑO, 2000) assume um caráter essencialmente convergente e evidencia-se, por outro lado, o fato de que o estudo das relações sociais de produção, que é o objeto da Economia Política e da Comunicação, pressupõe o conhecimento da evolução das forças produtivas. A inversão desses termos é o que caracteriza o materialismo vulgar.

Retomando o eixo da nossa argumentação, o estudo da história da televisão brasileira, na perspectiva da Economia Política da Comunicação, que importa a esse respeito ferramentas da microeconomia heterodoxa, é aquele da evolução das estruturas de mercado que constituem, primeiro, o processo de oligopolização da TV de massa, depois, a sua convivência com a TV segmentada, que representa outra trajetória tecnológica e segue também um movimento de oligopolização, bem estudado por Valério Brittos, na tese acima referida, constituindo aquilo que o autor chamou a fase da multiplicidade da oferta, até chegarmos à situação atual em que a lógica social da velha TV de massa, renovada pela digitalização, enfrenta a concorrência não só da TV segmentada, mas também dos novos meios digitais, das redes telemáticas, como a internet ou os videogames, das redes sociais etc., e o aparelho de TV torna-se o suporte daquilo que Brittos chegou a denominar "pluri-TV" (BRITTOS, 2012).

A oligopolização é entendida como a constituição de um mercado nacional unificado (diferente da concorrência praça a praça dos capitais relativamente pequenos do período anterior), com situações de liderança estabilizadas de longo prazo, com base em sólidas barreiras à entrada - tecno-produtivas ou político-institucionais (BRITTOS, 2004) - em relação à concorrência potencial, mas também à já implantada no setor, mas impedida de penetrar nas faixas de mercado fidelizadas pelas líderes, entre as quais se destacam os padrões tecnoestéticos (BOLAÑO, 2000).

Seguindo essas definições, conforme a bibliografia referida acima, chega-se a uma periodização em que os principais pontos de corte são os anos de 1965 (entrada da Globo no mercado e início da transição); 1969 (início da construção da primeira rede nacional e do processo de oligopolização que se consolida ao longo dos anos 1970); 
1995 (oligopolização da TV segmentada, privatização da internet nos Estados Unidos e início da fase da multiplicidade da oferta). Outras datas evidentemente são importantes, em especial os anos de 1997 (privatização das telecomunicações) e 2000 (crise das empresas de tecnologia que levará a um processo de concentração acelerado do mercado da internet).

Tomemos o primeiro ponto de corte, o ano de 1965, marcado pela entrada efetiva da Globo em um mercado concorrencial de 15 anos de idade, o qual será profundamente transformado a partir de então, tendo em vista a capacidade que a empresa terá, em função do volume de capital de que dispunha naquele momento, pela aliança com o capital internacional, que lhe concedia também conhecimento técnico e gerencial, de romper as frágeis barreiras à entrada das suas antecessoras. A mudança de regime no país, em 1964, é certamente um dos fatores externos fundamentais para se entender o processo e, na verdade, a transformação daquela estrutura de mercado está vinculada em grande medida ao projeto desenvolvimentista do regime militar, que incluía também a reforma do sistema de telecomunicações.

No entanto, o ano de 1964, do golpe militar, não pode ser definido como ponto de corte na periodização da TV brasileira, como também não pode ser o ano de 1962, da introdução do videoteipe. Por outro lado, a redemocratização não marcou nenhuma ruptura na trajetória do mercado de TV. Pelo contrário, sabemos que, mesmo com o final do regime militar, o seu projeto cultural permanece intacto - inclusive no concernente aos atores particulares específicos que exerciam hegemonia - até a privatização das telecomunicações na segunda metade dos anos 90 do século passado, quando as telefônicas estrangeiras entram e se posicionam para competir posteriormente, com o avanço da convergência, nos mercados do audiovisual, culminando com a mudança regulamentar da Lei SEAC, de 2011, que lhes garante exclusividade na oferta de pacotes de TV segmentada, num mercado reconfigurado, com a prática do triple play perfeitamente legalizada.

Note-se que o fato da chegada ao poder de um governo que se considerava de esquerda no país em nada mudou o panorama herdado do regime militar, embora a política e a regulação continuem sendo elementos fundamentais que influenciam as mudanças no setor. ${ }^{9}$ Generalizando, podemos dizer, em suma, que a relação entre fatores internos e externos na evolução de uma estrutura deve ser entendida nos termos

\footnotetext{
9 Para uma análise da situação atual e dos fatores de mudança em operação hoje, ver Bolaño, Mota e Nascimento (2015).
} 
do jogo dialético que separa as determinações de primeira e de última instância. Assim, se todo o processo faz parte, no final das contas, das exigências impostas pela evolução do capitalismo no país (que, por sua vez, como apontado acima, evolui no mesmo sentido, de acordo com a dinâmica centro-periferia), isto só ocorre concretamente pela mediação dos fatos que impactam diretamente sobre a estrutura e, na prática, a constituem. São esses os elementos irredutíveis, as invariantes estruturais que garantem a homogeneidade categorial necessária para o traçado de uma periodização. ${ }^{10}$

\section{III}

A adequação da história do pensamento comunicacional ao desenvolvimento dos sistemas de comunicação concretos ao longo de todo o século XX não representa mais que a compatibilidade entre dois sistemas de controle social característicos do capitalismo monopolista e, em especial, do modelo de desenvolvimento sob hegemonia norte-americana no qual ainda estamos metidos. A Economia Política da Comunicação e da Cultura, no interior do campo da Comunicação, representa, por assim dizer, a crítica imanente do pensamento comunicacional hegemônico.

O que se pretendeu defender na primeira parte deste estudo foi justamente a necessidade de uma demarcação histórica e epistemológica desse campo acadêmico, num momento, como o atual, sempre arriscado, em que o objeto da comunicação passa por uma transformação fundamental, decorrente da própria reestruturação produtiva iniciada nos anos 1970. Nessas condições, o poder de atração das explicações fetichistas da tecnologia só pode ser combatido recorrendo à gênese e às bases teóricas fundamentais do pensamento crítico marxista que caracteriza a alternativa global representada, no interior do campo da Comunicação, pela EPC e em especial pela EPC brasileira, que é o que está em tela neste artigo. Assim, a luta epistemológica no presente remete para a história institucional do campo e para a história do pensamento sobre ele.

\footnotetext{
10 Para encerrar este ponto, registre-se que a referida periodização do mercado brasileiro de televisão está centrada na TV comercial, absolutamente hegemônica no país, dada a opção por um modelo de regulação semelhante àquele norte-americano, imitado também na maior parte dos países da América Latina. A gênese dessa opção, distinta daquela mais comum na Europa, vem já da implantação do rádio. O sistema de TV pública estatal foi estudado na mesma perspectiva, definindo-se por sua condição de "complementaridade marginal" (VALENTE, 2009), ao passo que uma periodização na mesma linha foi realizada para o rádio (BOLAÑO, 2012). A EPC brasileira tem estudado ainda os mais variados mercados culturais e da comunicação (BOLAÑO; MANSO, 2009; SANTOS, 2016, entre outros) e se dedica hoje ao acompanhamento e crítica da economia política da internet (BOLAÑO et al, 2007, 2017; HORTA, 2017).
} 
Um aspecto interessante referente ao campo da Comunicação é o do sentido (e da rapidez) em que as mudanças no objeto impactam a disciplina, o que naturalmente amplia o referido poder de atração das explicações fetichistas da tecnologia, inclusive no interior da própria EPC. Assim, parte importante da esquerda acadêmica da área da comunicação esteve por longos 13 anos tão convicta da irrevogável derrota da chamada mídia hegemônica, da Indústria Cultural, dos grandes meios de comunicação de massa organizados em oligopólios, em favor das multidões empoderadas por aquele invento revolucionário e radicalmente democratizador, como imaginam, a Internet, que não conseguem entender o sentido do golpe institucional de 2016, acabando por imputar à mídia (aquela que já não podia nada), um poder que ela de fato não tem (não na medida que se imagina). Se antes a subestimavam, agora a superestimam.

Contra esses mitos e ilusões, é preciso afinar os instrumentos do pensamento crítico e realista. Na segunda parte deste artigo voltamos ao objeto mais tradicional da EPC, que se debruça sobre ele há já 30 anos no Brasil, a velha TV de massa, cuja capacidade de manipulação e sofisticação de estratégias ficaram tão patentes nos últimos anos. No espírito do texto, nos limitamos a indicar, nos termos mais gerais possíveis, os problemas de periodização, tomando a TV brasileira como exemplo de análise microeconômica e interdisciplinar paradigmático do campo da EPC, cujos principais representantes no país nunca se deixaram iludir. Ao contrário, dedicam-se, desde meados dos anos 1990, à crítica da economia política da Internet, esclarecendo tratar-se de um desenvolvimento inserido no movimento global do capital que se desdobra em reestruturação também no campo da produção cultural e da comunicação. Aqui também há uma longa história a ser considerada, mas não nos limites deste artigo.

\section{Referências}

BOLAÑO, César. Mercado brasileiro de televisão. São Paulo: EDUC, 1988.

Indústria cultural, informação e capitalismo. São Paulo: HUCITEC, 2000.

Economia política da comunicação e da cultura. Breve genealogia do campo e das taxonomias das indústrias culturais. In: BOLAÑO, César; BRITTOS, Valério; GOLIM, Cida. Economia da arte e da cultura. São Paulo: Observatório Itaú Cultural, 2010.

Considerações sobre a economia política do rádio no Brasil. Revista EPTIC Online, São Cristóvão, v. 14 n. 2, maio-ago. 2012. Disponível em:<https://seer.ufs.br/index.php/eptic/article/view/417/331>. Acesso em: 22 jun. 2018. 
EDISE, 2015.

Campo aberto. Para a crítica da epistemologia da comunicação. Aracaju:

BOLAÑO, César; HERSCOVICI, Alain; BRITTOS, Valério; MOURA, Fabio; MENEZES, Paulo Vinicius; VIEIRA, Eloy. Economia política da internet, v. 2. São Cristóvão: Editora UFS, 2017. Disponível em: <www.livraria.ufs.br>.Acesso em: 22 jun. 2018.

BOLAÑO, César; HERSCOVICI, Alain; CASTAÑEDA, Marcos; VASCONCELOS, Daniel. Economia política da internet, vol. 1. São Cristóvão: Editora UFS, 2007 [2. ed. 2011].

BOLAÑO, César; MANSO, Anna Carolina. Para uma economia política do audiovisual brasileiro. Cinema, televisão e o novo modelo de regulação da produção cultural. In: MELEIRO, Alessandra (Org.). Indústria cinematográfica e audiovisual brasileira. Cinema e Economia Política, v. 2. São Paulo: Escrituras, 2009, p. 87-100.

BOLAÑO, César; MOTA, Joanne; NASCIMENTO, Anderson.Introdução. In: BOLAÑO, César; BRITTOS, Valério (Org.). Rede Globo: 40 anos de poder e hegemonia.2. ed. rev. e amp. São Paulo: Barão de Itararé, 2015, p. 29-48.

BRITTOS, Valério (2001). Capitalismo contemporâneo, mercado brasileiro de televisão por assinatura e expansão transnacional. 2001. 425f. Tese (Programa de Pós-Graduação em Comunicação e Cultura Contemporâneas) - Faculdade de Comunicação, Universidade Federal da Bahia, Salvador, 2001.

. Televisão e barreiras: as dimensões estéticas e regulamentares. In: JAMBEIRO, Othon; BOLAÑO, César; BRITTOS, Valério (Org.). Comunicação, informação e cultura: dinâmicas globais e estruturas de poder. Salvador: EDUFBA, 2004, p. 15-42.

A economia política da comunicação no Brasil em perspectiva histórica. In: BOLAÑO, César (Org.). Comunicação e a crítica da economia política: perspectivas teóricas e epistemológicas. São Cristóvão: Editora UFS, 2008, p. 193-208.

2012.

A televisão em todo lugar, a toda hora. São Leopoldo: UNISINOS, mimeo,

BOURDIEU, Pierre.Laproduction de lacroyance. Contribution à une économiedesbienssymboliques.In: Actes de laRechercheenSciencesSociales, 13, février, p. 4-43, 1977.

O campo científico. In: ORTIZ, Renato (Org.). Pierre Bourdieu: sociologia. São Paulo: Ática, 1983, p.122-155. (Grandes Cientistas Sociais, n.39).

CAPPARELLI, Sergio. Televisão e capitalismo no Brasil. Porto Alegre: LPM, 1984.

FOUCAULT, Michel. La arqueologíadel saber. México: Siglo XXI, 1970.

FURTADO, Celso. Prefácio a nova economia política. Rio de Janeiro: Paz e Terra, 1977. 
HERSCOVICI, Alain. Economia da cultura e da comunicação. Vitória: Fundação Ceciliano Abel de Almeida; UFES, 1995.

HORTA, Isabela.O desenvolvimento da internet e os grandes bancos: um estudo a partir das iniciativas do Bradesco. 2017. 177 f. Dissertação (Mestrado em Comunicação) Universidade de Brasília, Brasília, 2017.

LOPES, Ruy. Informação, conhecimento e valor. São Paulo: Radical Livros, 2006.

MARX, Karl. Teorias sobre laplusvalia. México: Fondo de Cultura Económica, 18621863.

MELO, José Marques; MELO, PatriciaBandeira.Economiapolítica da comunicação: vanguardismonordestino. Recife: Fundação Joaquim Nabuco; EditoraMassangana, 2013.

RUBIN, Isak. História do pensamento econômico. Rio de Janeiro: UFRJ, 1927.

SANTOS, Verlane. Los "circuitos musicales" en Sergipe: contradicciones de laproducción y distribución de contenido musical del estado más pequeño de Brasil. Alcance, Revista Cubana de Información y Comunicación, La Habana, v. 5, n. 10, p. 4-26, [mayo-agosto] 2016.

SIMIS, Anita; LOPES, Ruy. Economia política da comunicação. In: CASTRO, Daniel; MELO, José Marques de; CASTRO, Cosette (Org.) Panorama da comunicação e das telecomunicações no Brasil. v. 2. Brasília: IPEA, 2010, p. 163-174.

SLATER, Phil. Origem e significado da Escola de Frankfurt: uma perspectiva marxista. Rio de Janeiro: Editora Zahar, 1978.

SODRÉ, Muniz. Comunicação: um campo em apuros teóricos. In: Matrizes, São Paulo, v. 5. n. 2, p. 11-27, jan.-jul. 2012. Disponível em: <https://www.revistas.usp.br/matrizes/article/view/38325/41179>. Acesso em: 22 jun. 2018.

VALENTE, Jonas. TV pública no Brasil: a criação da TV Brasil e sua inserção no modo de regulação setorial da televisão brasileira. 2009. 206 f. Dissertação (Mestrado em Comunicação) - Universidade de Brasília, Brasília, 2009. Disponível em: <http://repositorio.unb.br/bitstream/10482/5468/1/2009_JonasChagasLucioValente.pdf> . Acessoem: 22 jun. 2018.

Submetidoem: 29.03.2018

Aprovadoem: 14.06.2018 